Brazilian Journal

of Chemical

Engineering

\title{
EPOXIDATION OF JATROPHA METHYL ESTERS VIA ACIDIC ION EXCHANGE RESIN: OPTIMIZATION AND CHARACTERIZATION
}

\author{
Aishah Derahman ${ }^{1}$, Zurina Z. Abidin ${ }^{1 *}$, Francisco Cardona ${ }^{2}$, Dayang R. A. Biak ${ }^{1}$, \\ Paridah Md. Tahir ${ }^{3}$, Khalina Abdan ${ }^{3}$ and Kan Ern Liew ${ }^{4}$ \\ ${ }^{1}$ Universiti Putra Malaysia, Faculty of Engineering, Department of Chemical and Environmental Engineering, Selangor, Malaysia. \\ E-mail: zurina@upm.edu.my - ORCID: 0000-0002-3998-2545; ORCID: 0000-0002-3029-6581 \\ ${ }^{2}$ Universiti Putra Malaysia, Faculty of Engineering, Aerospace Manufacturing Research Centre, Selangor, Malaysia. \\ ${ }^{3}$ Universiti Putra Malaysia, Institute of Tropical Forestry and Forest Products, Selangor, Malaysia. ORCID: 0000-0002-2961-6031; \\ ORCID: 0000-0002-5370-6336 \\ ${ }^{4}$ Aerospace Malaysia Innovation Centre, Selangor, Malaysia.
}

(Submitted: July 16, 2018 ; Revised: December 4, 2018 ; December 5, 2018)

\begin{abstract}
Plant oils and their derivatives have been vigorously exploited as alternatives for synthesis of epoxides due to depletion of petroleum resources. In this study, crude jatropha oil (CJO) was subjected to a transesterification process to form jatropha methyl esters (JME) using peroxyacetic acid generated in situ from hydrogen peroxide and acetic acid via an acidic ion exchange resin (AIER). The effect of temperature, molar ratio of hydrogen peroxide to unsaturation, molar ratio of acetic acid to unsaturation, and catalyst loading were investigated. This study revealed that the maximum $89.9 \%$ relative conversion to oxirane rings was achieved after $6 \mathrm{~h}$ with the optimal reaction conditions of temperature at $70{ }^{\circ} \mathrm{C}$, the molar ratio of hydrogen peroxide to unsaturation of $1.5 \mathrm{~mol}$, the molar ratio of acetic acid to unsaturation of $0.5 \mathrm{~mol}$, and catalyst loading of $16 \%$. Fourier Transform Infrared (FTIR) spectra of the epoxidized jatropha methyl esters (EJME) showed oxirane peaks (doublet) at 825 and $843 \mathrm{~cm}^{-1} .{ }^{1} \mathrm{H}$ NMR confirmed the diepoxide group at $2.85 \mathrm{ppm}$ and $2.98 \mathrm{ppm}$, while the diepoxide signals of ${ }^{1} \mathrm{C}$ NMR were present at $56.88-57.06 \mathrm{ppm}$. Production of bio-epoxides from Jatropha methyl esters hence looks promising with favorable physicochemical properties, availability, and versatility.

Keywords: Jatropha; Bio-epoxy resins; Epoxidation; FAME.
\end{abstract}

\section{INTRODUCTION}

Petroleum is the major source for production of polymers, plasticizers, lubricants, and others. The depletion of petroleum supply and the growing demand for new feedstock in many countries have encouraged researchers to find alternative resources. Plant oils and their derivatives have attracted the attention of researchers in various fields due to their availability, non-toxicity, and, most importantly, modifiability by chemical, physical, or enzymatic methods. Moreover, the usage of synthetic epoxy resin derived from petroleum raises many safety issues with regards to health and environmental impacts. Bioresources derived from plant oil are an excellent substitute because they are available in abundance and green.

A plant oil derivative, Jatropha methyl esters (JME) have high iodine value which makes them suitable to be used as raw materials in the production of bioepoxides. These epoxidized Jatropha methyl esters (EJME) with high oxirane value would be an excellent potential source for bio-epoxy resins.

Chemical modifications such as epoxidation are commonly used in synthesizing bio-epoxy resin or epoxide due to the ease of process handling at moderate conditions. It is described as the formation of an oxirane

\footnotetext{
* Corresponding author: Zurina Z. Abidin - E-mail: zurina@upm.edu.my
} 
group by the reaction of peroxyacids and aromatic double bonds. Basically, this process is conducted with the presence of organic acid (formic or acetic acid), hydrogen peroxide, and catalysts (Campanella et al., 2008; Mushtaq et al., 2013; Latif et. al., 2019). For instance, epoxidation by an environmental friendly AIER catalyst exhibits high selectivity and minimum side reactions.

The main content of a bio-epoxy resin is the oxirane ring, which is very reactive and enables epoxides to be used as biolubricants (Borugadda and Goud, 2015a), reactive diluents (Das and Karak, 2009), and stabilizers in PVC and plasticizers (Chua et al., 2012). Besides, they have also been used as intermediates in the production of polyols and polyurethanes (Chen et al., 2015). Production of bio-epoxy resins from plant oils has been reported previously from jatropha oil (Goud et al., 2010; Latif et al., 2019), rubber seed oil (Okieimen et al., 2005), cottonseed oil (Carbonell-Verdu et al., 2015), soybean oil (Cheng et al., 2015), sunflower oil (Benaniba et al., 2007), Karanja oil (Bajwa et al., 2016), and hemp oil (Cooney et al., 2011).

Not only plant oils have been used as raw material for the synthesis of biopolymers, their derivatives also have been gaining attention because of their excellent performances. A number of researchers have reported on epoxidation using derivatives of plant oils such as fatty acid methyl esters (Campanella et al., 2008), linoleic acid (Hong et al., 2015), and alkenes (Ghiron et al., 2005). FAME, otherwise is popularly known as biodiesel, currently has been used as an alternative for diesel fuel due to its special attributes, including that it is highly available, non-toxic and biodegradable (Satyanarayana and Muraleedharan, 2011; Kay and Yasir, 2012). It is produced from a transesterification process of triglyceride in crude plant oils with the assistance of alcohol and an acid or a base catalyst. Even though FAME has been used mainly in the automobile industry, the accessibility of its structure to undergo further chemical modifications such as the transformation of double bonds into oxirane ring units has opened a new dimension to oleochemical synthesis.

Many have reported on the production of bio-epoxides from crude jatropha oil (CJO) using epoxidation (Goud et al., 2010, 2007; Rios et al., 2011; Sammaiah et al., 2014; Latif et al., 2019). The factors affecting the process are reaction temperature, molar ratio hydrogen peroxide to unsaturation, molar ratio of organic acid to unsaturation, concentration of catalyst, and stirring speed. Instead of using $\mathrm{CJO}$, this study focused on the use of jatropha methyl esters (JME) to produce bio-epoxy. Normally, epoxidized fatty acid derived from plant oils are found to have higher oxirane content, more reactivity, and lower viscosity compared to epoxidized crude oils (Wang and Schuman, 2012). This characteristic is very important in the production of epoxy. Table 1 shows a comparison of
Table 1. Comparison properties of CJO and JME.

\begin{tabular}{lcc}
\hline \multicolumn{1}{c}{ Properties } & CJO & JME \\
\hline Density at $15^{\circ} \mathrm{C}\left(\mathrm{kg} / \mathrm{m}^{3}\right)$ & 918 & 880 \\
Viscosity at $40^{\circ} \mathrm{C}\left(\mathrm{mm}^{3} / \mathrm{s}\right)$ & 35.4 & 4.84 \\
Acid value $(\mathrm{mg} \mathrm{KOH} / \mathrm{g})$ & 11.0 & 0.24 \\
Iodine value & 101 & 104 \\
Saponification value & 194 & 190 \\
\hline
\end{tabular}

the properties of CJO and JME. JME possessed lower density and viscosity but higher reactivity than CJO (Bobade et al., 2013), and this makes it attractive for bioepoxy production.

Up to date, no previous study has been reported on the epoxidation of JME resins. Therefore, the objective of this work was to investigate the reaction parameters affecting the epoxidation process of jatropha methyl esters. In addition, spectroscopic characterization such as FTIR and NMR were used to confirm the formation of epoxide groups in the epoxidized JME. Bio-epoxides produced through epoxidation of JME have potential as plasticizers and stabilizers in PVC, as bio-lubricants, and as a polymeric coating.

\section{EXPERIMENTAL}

\section{Materials}

Jatropha curcas seed oil used in this work was purchased from BATC Development Berhad (Bionas) and was used without further purification. Anhydrous methanol $\left(\mathrm{CH}_{3} \mathrm{OH}\right)$, sulfuric acid $\left(\mathrm{H}_{2} \mathrm{SO}_{4}\right)$, sodium methoxide $\left(\mathrm{CH}_{3} \mathrm{ONa}\right)$, and anhydrous sodium sulfate $\left(\mathrm{Na}_{2} \mathrm{SO}_{4}\right)$ were used during the transesterification process. These chemicals were purchased from R\&M Chemicals Ltd. without further purifications. Hydrogen peroxide $\left(50 \% \mathrm{H}_{2} \mathrm{O}_{2}\right)$ was purchased from Qrec Sdn Bhd, glacial acetic acid $\left(\mathrm{CH}_{3} \mathrm{COOH}\right)$ from R\&M, and Amberlite IR-120 from Sigma Aldrich.

\section{Experimental setup and procedures \\ Production of jatropha methyl esters}

Production of jatropha methyl esters was conducted using a transesterification method. Based on the preliminary tests, \%FFA of crude jatropha oil was calculated to be $15.7 \%$ which was considered high. A high content of FFA creates a problem in the separation of the methyl ester layer from the glycerin fraction due to the formation of soap. Hence, a twostage transesterification method was used (Deng et al., 2010; Jain and Sharma, 2010). The process was conducted in a $1000 \mathrm{~mL}$ three-necked flask completed with a mechanical stirrer, a reflux condenser, and a thermometer under atmospheric pressure. The experiment was performed at optimized conditions of methanol $\left(\mathrm{CH}_{3} \mathrm{OH}\right)$, sulfuric acid $\left(\mathrm{H}_{2} \mathrm{SO}_{4}\right)$, and sodium methoxide $\left(\mathrm{CH}_{3} \mathrm{ONa}\right)$ adapted from Rashid et al. (2012). The molar ratio of methanol to oil was reported to be optimum at $6: 1$ and percentage weight 
of catalyst is $1 \%$ (w:w) of oil. Other than the optimal values, the reaction is incomplete and leads to soap formation (Rashid and Anwar, 2008)

Percentage weight of obtained methyl esters was calculated using the equation below:

Biodiesel yield $(w t \%)=\frac{\text { gram of methyl esters produced }}{\text { gram of jatropha oil used in production }} \times 100$

The obtained methyl esters were subjected to physicochemical tests as well as FTIR and NMR analysis to confirm the formation of methyl esters and removal of glycerol. Methyl esters were stored for further used in the epoxidation process.

\section{Epoxidation of jatropha methyl esters}

Epoxidation reaction was carried out in a threenecked round-bottom flask $(1000 \mathrm{~mL})$, equipped with a mechanical stirrer, and placed in a water bath which could be controlled to within $+1{ }^{\circ} \mathrm{C}$ of the desired temperatures. A separatory funnel was inserted in the left neck to add dropwise the hydrogen peroxide. After the addition of the hydrogen peroxide completed, it was replaced with a thermometer to record the temperature of the epoxidation process. Another neck was sealed and opened intermittently for sample withdrawal.

The epoxidation method of Goud et al. (2006) was adopted for all of the experiments. An appropriate mass of JME (239.23 g) was added in the flask with the necessary amount of acetic acid $(0.5 \mathrm{~mol})$ and Amberlite (16\%) catalyst based on the percentage weight of organic phase (oil and acetic acid) (Borugadda and Goud, 2015a). The mixture was subjected to continuous stirring for $30 \mathrm{~min}$, followed by addition of $30 \%$ of hydrogen peroxide $(1.5 \mathrm{~mol})$. Hydrogen peroxide was added to the flask drop-wise within half an hour. After the addition of hydrogen peroxide was completed, the reaction was continued for $10 \mathrm{~h}$. The rapid stirring was maintained throughout the experiments so that a fine dispersion of oils was achieved. At 1-h intervals, $50 \mathrm{~mL}$ of mixture was drawn off using a $50 \mathrm{~mL}$ glass pipette. When the addition of hydrogen peroxide was completed, time was set to zero.

The collected samples were placed in a $50 \mathrm{~mL}$ separatory funnel and the bottom layer which consisted of acetic acid, hydrogen peroxide, and Amberlite, was drawn off. The purification process of the upper layer (bio-epoxy resins) was conducted using 5\% diethyl ether together with warm and cold water. First, the resin was washed with successive portion of diethyl ether, followed by cold water and finally, hot water with the purpose to remove residual fatty acid or unreacted chemicals. The solution was dried over anhydrous sodium sulfate $(1.5 \% \mathrm{w}: \mathrm{w})$ overnight in an oven at $70{ }^{\circ} \mathrm{C}$ to remove any traces of water. All samples were collected in $5 \mathrm{~mL}$ glass vials and sent for oxirane content analysis.

\section{Analytical methods \\ Oxirane Oxygen Content}

The determination of relative conversion to oxirane was necessary to determine the quality of oxirane as well as the efficiency of the epoxidation process. The oxirane content of each sample was determined using the direct method with hydrobromic acid solution presented by Paquot (1979). From the oxirane content, the percentage relative conversion to oxirane was determined using the following formula:

Relative conversion to oxirane $(\%)=\frac{\mathrm{O}_{\text {exp }}}{\mathrm{O}_{\text {theo }}} \times 100$

where $\mathrm{O}_{\exp }$ and $\mathrm{O}_{\text {theo }}$ are the experimental and theoretical oxirane oxygen values (\%) respectively. $\mathrm{O}_{\text {theo }}$ is determined using the following equation:

$\mathrm{O}_{\text {theo }}=\left[\frac{\left(\frac{\mathrm{IV}_{0}}{2 \mathrm{~A}_{\mathrm{i}}}\right)}{100+\left(\frac{\mathrm{IV}}{2 \mathrm{~A}_{\mathrm{i}}}\right)\left(\mathrm{A}_{0}\right)}\right] \times \mathrm{A}_{0} \times 100$

where $A_{i}(126.9)$ and $A_{0}(16.0)$ are the atomic weights of iodine and oxygen, respectively, and $\mathrm{IV}_{0}$ is the initial iodine value of the oil sample.

\section{FTIR Spectroscopy Analysis}

The Fourier Transform Infrared (FTIR) analysis was carried out to determine the functional group in the CJO, JME, and EJME. The spectra were recorded on an FTIR Perkin-Elmer spectrophotometer model Spectrum-1000 (Perkin-Elmer, Norwalk, CT, USA). A potassium bromide $(\mathrm{KBr})$ pallet was used to determine the background signal. The spectra were obtained over the frequency range $4000-650 \mathrm{~cm}^{-1}$ at the resolution of $4 \mathrm{~cm}^{-1}$ and the final output was in $\%$ transmittance.

\section{NMR Spectral analysis}

The NMR samples were prepared by dilution with deuterated chloroform at a ratio 1:1 by volume and analyzed in $5 \mathrm{~mm}$ NMR tubes. NMR spectra were recorded on a JEOL-ECP 500 NMR spectrophotometer operating at $400.13 \mathrm{MHz}$. The results were analyzed using Delta 5.0.4 software.

\section{RESULTS AND DISCUSSION}

Physicochemical tests were conducted and the results for all three samples of CJO, JME, and EJME are shown in Table 2. The iodine value of JME was 
Table 2. Physicochemical characteristic of CJO, JME and EJME.

\begin{tabular}{lccc}
\hline \multicolumn{1}{c}{ Properties } & CJO & JME & EJME \\
\hline Iodine value $(\mathrm{g} 12 / 100 \mathrm{~g})$ & $103.1 \pm 0.6$ & $107.7 \pm 1.4$ & $9.9 \pm 0.9$ \\
Acid value $(\mathrm{Mg} \mathrm{KOH} / \mathrm{g})$ & $15.7 \pm 0.7$ & $0.84 \pm 0.1$ & - \\
Free fatty acid $(\%)$ & $7.89 \pm 0.7$ & $0.42 \pm 0.1$ & - \\
Saponification value $(\mathrm{Mg} \mathrm{KOH} / \mathrm{g})$ & $185.6 \pm 2.2$ & $175.31 \pm 3.2$ & - \\
Density at $30^{\circ} \mathrm{C}\left(\mathrm{kg} / \mathrm{m}^{3}\right)$ & $893 \pm 1.8$ & $868 \pm 0.9$ & $920 \pm 1.5$ \\
Dynamic viscosity at $30^{\circ} \mathrm{C}(\mathrm{cP})$ & $46.8 \pm 0.7$ & $5.7 \pm 0.5$ & $11.55 \pm 0.6$ \\
Kinematic viscosity at $30^{\circ} \mathrm{C}\left(\mathrm{mm}^{2} / \mathrm{s}\right)$ & $52.41 \pm 0.8$ & $6.56 \pm 0.6$ & $12.55 \pm 0.7$ \\
Specific gravity & $0.89 \pm 1.8$ & $0.87 \pm 0.9$ & $0.92 \pm 1.5$ \\
\hline
\end{tabular}

within the same range as CJO because there was no reduction or addition of double bonds during transesterification, only glycerol was removed from the triglycerides. The viscosity of JME and EJME were very low compared to CJO, which was due to the formation of monoglycerides in JME and oxirane rings in EJME. The acid value and FFA for JME reduced to $0.84+0.1 \%$ and $0.42+0.1 \%$, respectively, because of the pretreatment steps. This reduced the JME saponification value to $175.31+3.2 \mathrm{mg} \mathrm{KOH} / \mathrm{g}$. Similar results have been reported by previous works ( $\mathrm{Lu}$ et al., 2009). Highest percentage yield of JME obtained was $90.6+1 \%$ with a total reaction time of 4 h. JME had lower density and viscosity compared CJO due to the removal of glycerol. However, the density of EJME was higher than CJO and JME due to the formation of oxirane rings. The viscosity of EJME was also slightly higher than JME but was still lower than CJO. Fatty acid composition of methyl esters was as follows: $\mathrm{C} 16: 0=15.1 \%, \mathrm{C} 18: 0=9.9 \%, \mathrm{C} 18: 1=$ $41.7 \%, \mathrm{C} 18: 2=31.0 \%$.

Epoxidation reactions catalyzed by AEIR using peroxyacetic acid generated in situ were conducted to investigate the effect of four main reaction variables on the epoxidation process. The studied variables were reaction temperature and time, molar ratio of hydrogen peroxide to unsaturation, molar ratio of acetic acid to unsaturation, and catalyst loading. Graphs of relative conversion to oxirane (RCO) with respect to reaction time were plotted for each variable.

\section{Effect of reaction temperature}

Temperature plays the most important role in the epoxidation reaction (Campanella et al., 2008) and the effect of temperature on the epoxidation process was investigated at $30,50,70$, and $85^{\circ} \mathrm{C}$. The results of relative percentage conversion to oxirane were demonstrated in Fig. 1. RCO increased linearly with time before it gradually decreased. As shown, the rate of epoxidation increased when the temperature increased from $30{ }^{\circ} \mathrm{C}$ to $85{ }^{\circ} \mathrm{C}$. At a reaction temperature of $30{ }^{\circ} \mathrm{C}$, the highest $\mathrm{RCO}$ of $54.8 \%$ was obtained when the experiment was conducted for $8 \mathrm{~h}$. As the reaction temperature was increased to $50{ }^{\circ} \mathrm{C}, \mathrm{RCO}$ increased to $68.3 \%$ and the reaction time was reduced to $7 \mathrm{~h}$. A reaction temperature of $70{ }^{\circ} \mathrm{C}$ was concluded to be

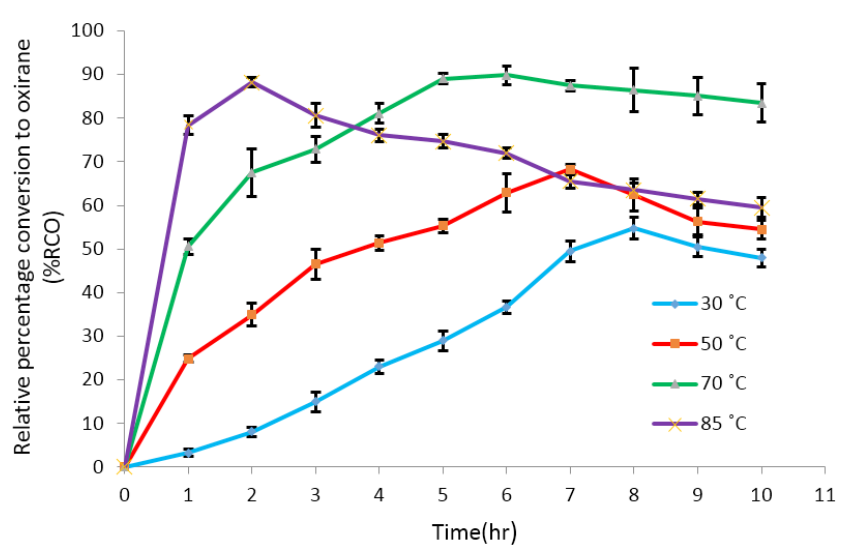

Figure 1. Effect of reaction temperature on relative percentage conversion to oxirane. Reaction conditions: JME, 1 mol; HP to unsaturation molar, 1.5:1; AA to unsaturation molar ratio, $0.5: 1$; catalyst loading, $16 \%$;stirring speed, $1500 \mathrm{rpm}$.

the optimal condition because it provided the highest $\mathrm{RCO}(89.8 \%)$ in the shortest time, which was $6 \mathrm{~h}$.

A similar optimum reaction temperature was reported by Goud et al. (2007) with $88 \%$ of RCO. As shown, the RCO for reaction condition at $85{ }^{\circ} \mathrm{C}$ decreased rapidly after it reached a maximum point of $88.2 \%$ after $2 \mathrm{~h}$. A higher reaction temperature promotes more oxirane cleavages to occur, which then leads to the formation of glycol in the final product (Dinda et al., 2008; Mungroo et al., 2008). At a high reaction temperature, water which was the product of the reaction between hydrogen peroxide and acetic acid can initiate oxirane ring cleavage with acetic acid and later form hydroxyl groups on the fatty ester backbone (Saithai et al., 2013). High temperature promotes hydrolysis (oxirane cleavage), which was indicated by the formation of glycol (Goud et al., 2007; Goud et al., 2006; Mungroo et al., 2008). Percentage of conversion to glycol in the final product can be calculated using the method by May (1973). Moreover, the formation of glycol can be verified using FTIR and NMR analysis. From Fig. 1, it can be concluded that the time required to attain the maximum $\mathrm{RCO}$ was different for each reaction temperature. It was agreed that moderate reaction conditions were more favorable to attain the maximum yield with minimum impurities (Goud et al., 2006). 


\section{Effect of molar ratio of hydrogen peroxide to unsaturation}

The role of hydrogen peroxide is directly associated with acetic acid in the formation of peroxyacetic acid. However, its role is more significant because it is consumed during the reaction, but acetic acid is regenerated after their oxygen atom is utilized (Goud et al., 2010; Mushtaq et al., 2013).

The effect of hydrogen peroxide to ethylenic unsaturation molar ratio on the epoxidation process was studied at $0.8,1.1,1.5$, and $2.0 \mathrm{~mol}$ of hydrogen peroxide for $1 \mathrm{~mol}$ of JME. As shown in Fig. 2, RCO initially increased with the increasing molar ratio. When the molar ratio was increased from 0.8 to 1.1 , the rate of epoxidation increased progressively, indicated by the RCO increase from $75.9 \%$ to $88.95 \%$. Further increment of the molar ratio to $1.5 \mathrm{~mol}$ gave the highest $\mathrm{RCO}$ of $89.6 \%$ at $6 \mathrm{~h}$. When the experiment was conducted at a higher molar ratio, the rate of epoxidation increased higher than that of $1.5 \mathrm{~mol}$ reaction from 0 to $2 \mathrm{~h}$ but only achieved the highest RCO of $88.5 \%$ at $5 \mathrm{~h}$, which is less than the $1.5 \mathrm{~mol}$ reaction.

After the reaction was extended further, RCO was observed to decrease due to oxirane cleavage. Hence, the optimal condition for molar ratio of hydrogen peroxide to ethylenic unsaturation was concluded to be 1.5 mol. Sinadinović-Fišer et al. (2012) had reported similar molar ratio of hydrogen peroxide as the optimal value, with lower $\mathrm{RCO}, 78.3 \%$, at a longer reaction time of $8 \mathrm{~h}$. This may be due to the feedstock used, which was crude Jatropha oil, while in this reaction, Jatropha methyl esters were used instead. The RCO value decreased to $88.5 \%$ after the molar ratio was increased to $2 \mathrm{~mol}$. This was because a higher hydrogen peroxide concentration promoted the acceleration of oxirane ring opening, which led to the poor stability of the final product (Goud et al., 2006).

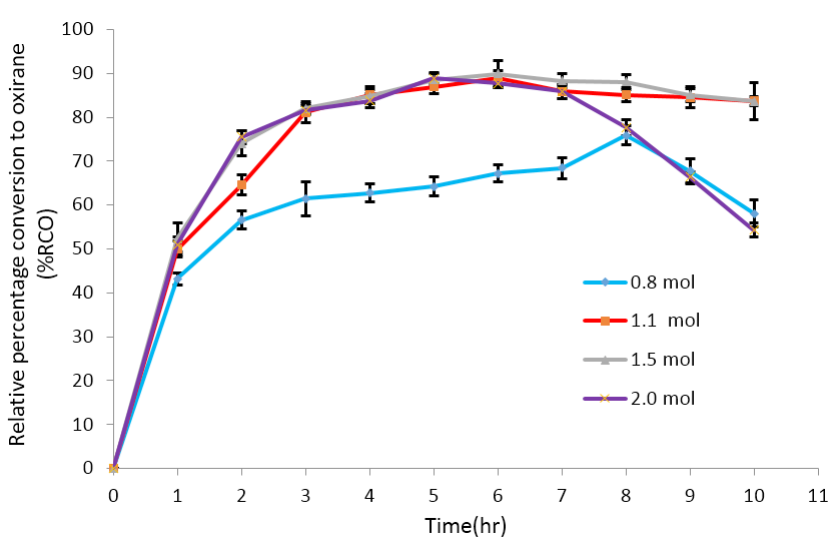

Figure 2. Effect of hydrogen peroxide per mole of ethylenic unsaturation on relative percentage conversion to oxirane. Reaction conditions: JME, 1 mol; AA to unsaturation molar ratio $0.5: 1$; catalyst loading $16 \%$ of oil; temperature $70{ }^{\circ} \mathrm{C}$; stirring speed $1500 \mathrm{rpm}$.
Effect of molar ratio of acetic acid to unsaturation

Acetic acid is a better oxygen carrier compared to formic acid (Dinda et al., 2008; Goud et al., 2007; Mungroo et al., 2008); hence, acetic acid was chosen as the oxygen carrier in this reaction. The effect of acetic acid to ethylenic unsaturation molar ratio on the epoxidation process was studied at $0.3,0.5,0.65$, and 1.0 mol. As shown in Fig. 3, the rate of epoxidation increased significantly when the molar ratio was increased from 0.3 to 0.5 mol. Highest RCO was obtained at $0.5 \mathrm{~mol}$ with the value of $89.9 \%$ at $6 \mathrm{~h}$. After the molar ratio was increased to 0.65 and $1 \mathrm{~mol}$, the rate of epoxidation increased and highest RCO was achieved faster than that at $0.5 \mathrm{~mol}$ reaction. However, as depicted in Fig. 3, RCO was reduced to $88.5 \%$. As a conclusion, the rate of the epoxidation reaction increased with increasing acid concentrations, resulting in a higher conversion of double bonds to oxirane ring. At the same time, the increased acid concentration can also lead to the destruction of oxirane rings, thereby reducing epoxidation yield. The optimal molar ratio of acetic acid was identified to be $0.5 \mathrm{~mol}$ to ethylenic unsaturation, which was similar with previous reports (Goud et al., 2010; Sinadinović-Fišer et al., 2012).

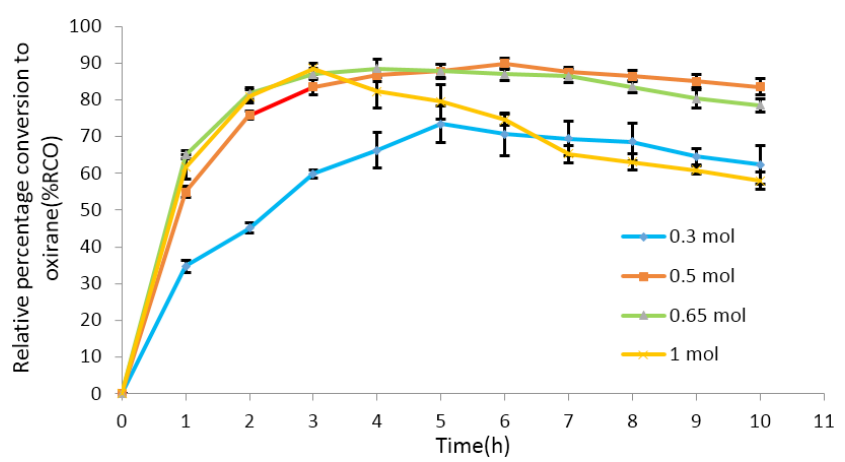

Figure 3. Effect of acetic acid per mole of ethylenic unsaturation on relative percentage conversion to oxirane. Reaction conditions: JME $1 \mathrm{~mol}$; HP to unsaturation molar ratio $1.5: 1$; catalyst loading $16 \%$; temperature $70{ }^{\circ} \mathrm{C}$; stirring speed $1500 \mathrm{rpm}$.

\section{Effect of catalyst loading}

Amberlite IR-120 is among the best heterogeneous catalyst with high selectivity to the formation of epoxides and high oxirane conversion (Borugadda and Goud, 2014). The effect of catalyst loading on the epoxidation process was studied at $5 \%, 10 \%, 15 \%$, and $20 \%$. Fig. 4 shows the results obtained for the variations of catalyst loading. An increase in catalyst loading leads to an increase in both total active volume and total surface area of the catalyst. Hence, it increased the rate of in situ peroxyacetic acid formation.

It was observed that an increase in catalyst loading resulted in an increase in the initial rate of epoxidation as well as an increase in RCO. As shown in Fig. 4, the rate of epoxidation reaction increased when the 


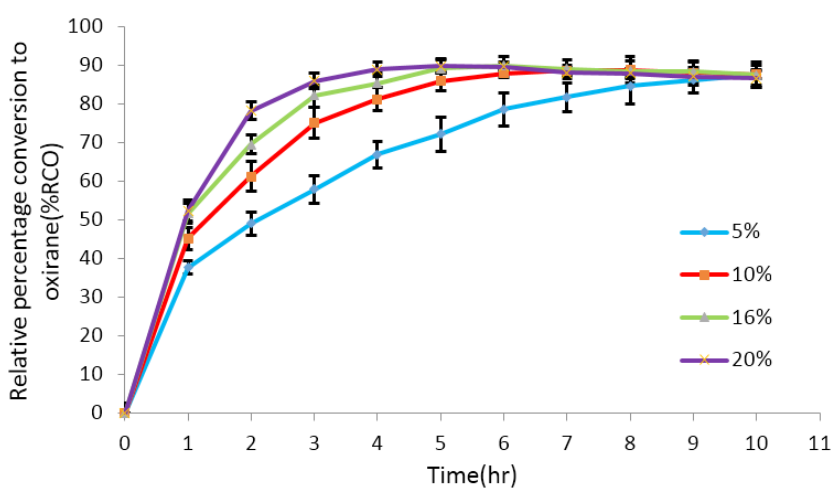

Figure 4. Effect of catalyst loading on relative percentage conversion to oxirane. Reaction conditions: JME, 1 mol; HP to unsaturation molar ratio, 1.5:1; AA to unsaturation molar ratio, $0.5: 1$; temperature, $70{ }^{\circ} \mathrm{C}$; stirring speed, $1500 \mathrm{rpm}$.

percentage of catalyst was increased from $5 \%$ to $20 \%$. The lowest rate was achieved at $5 \%$ with the maximum $\mathrm{RCO}$ of $87.5 \%$ was obtained at $10 \mathrm{~h}$ as indicated in the graph. Further increase of the catalyst concentration to $10 \%$ increased the $\mathrm{RCO}$ to $88.7 \%$ at $8 \mathrm{~h}$. Maximum RCO was achieved at $16 \%$ catalyst loading. At similar reaction conditions, Goud et al. (2007) reported that $16 \%$ of catalyst loading attained $88 \%$ yield. Hence, it was concluded that $16 \%$ was the optimal condition for catalyst loading.

Since the AIER has been reported to affect the selectivity, it is desirable to study the epoxidation of JME in bulk with an objective of obtaining higher oxirane selectivity compared to homogenous catalyst (Goud et al., 2007). High catalyst loading does not affect the production cost because the catalyst can be recovered from the final product and recycled. A report by Mungroo et al. (2008) stated that, at the end of the reaction, the catalyst was removed by filtration and washed with water and diethyl ether. The washed catalyst was air-dried and reused. This clearly indicates that the heterogeneous catalyst, AIER, can be recycled with little loss of activity. In this study, the recovery method of the catalyst is very simple using filter paper. The low viscosity of EJME accelerates the recovery process to less than $1 \mathrm{~h}$.

\section{FTIR analysis}

The spectroscopic properties of CJO, JME, and EJME were studied by FTIR spectroscopy. FTIR is a sensitive technique appropriate to monitor the formation of FAME and oxirane ring in transesterification and epoxidation processes, respectively. FTIR spectra demonstrated the presence of peaks in the range of $3002-3008 \mathrm{~cm}^{-1}$ associated with the stretching of C-H attached to double bonds. As can be seen from Fig. 5, the presence of unsaturation in both CJO and JME was confirmed by the presence of a peak at $3009 \mathrm{~cm}^{-1}$.

The formation of oxirane ring after the epoxidation process was also demonstrated in Fig. 5. It can be observed by the disappearance of the peak at 3009 $\mathrm{cm}^{-1}$ in JME and the appearance of oxirane peaks (doublet) at 825 and $843 \mathrm{~cm}^{-1}$. This was in accordance with the reports of previous works, that oxirane ring exists in the range of 820 to $843 \mathrm{~cm}^{-1}$ (Petrovic et al., 2002; Saremi et al., 2012; Borugadda and Goud, 2014). Moreover, FTIR was not only used to monitor the formation of oxirane ring, but also to monitor the formation of any side reactions such as oxirane ring opening (Borugadda and Goud, 2015b).

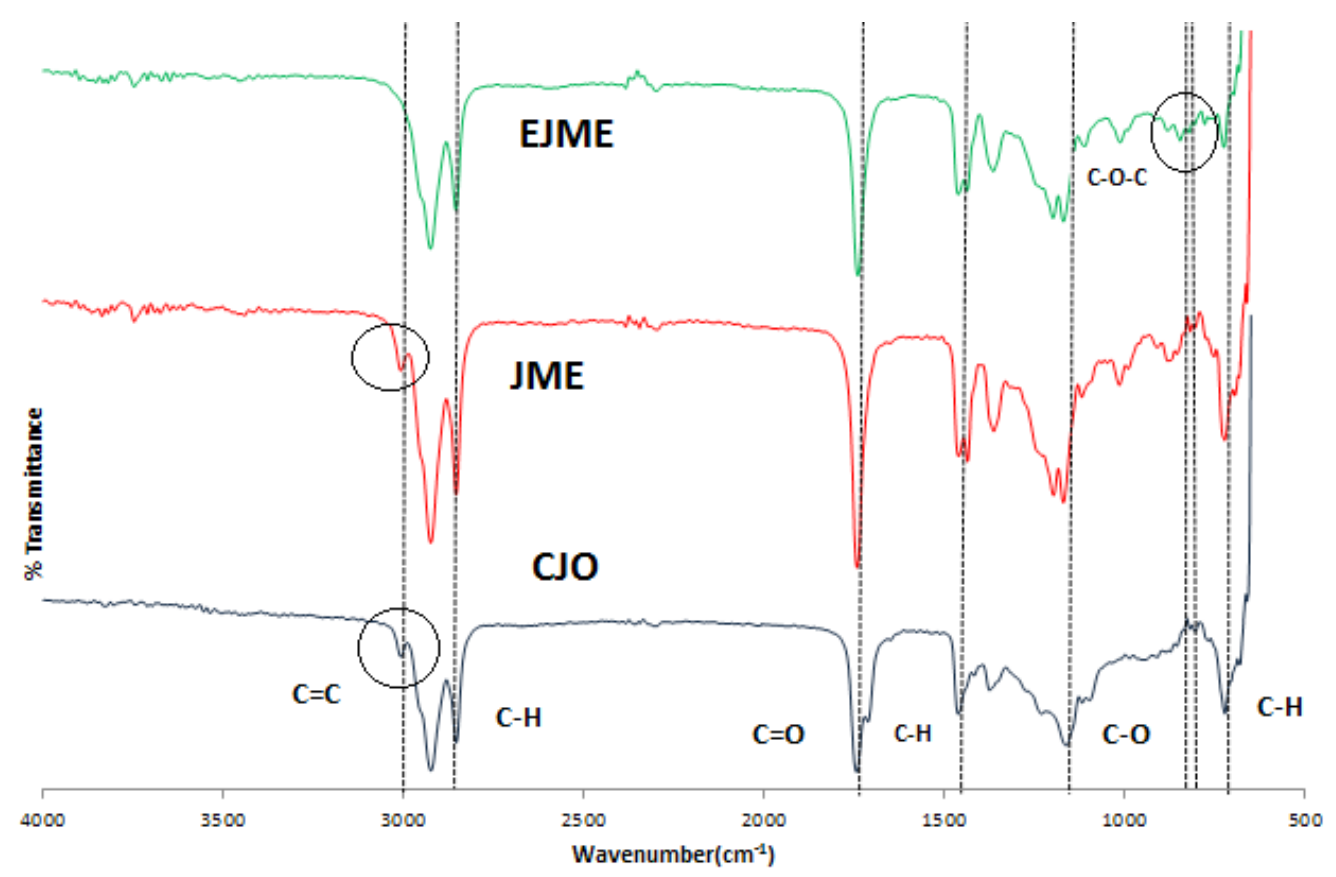

Figure 5. FTIR spectra of CJO, JME and JME epoxide. 
The absence of hydroxyl peaks in the range of $3000-3500 \mathrm{~cm}^{-1}$ (O-H range) proved that minimum oxirane cleavage had occurred in the epoxidation process at optimum conditions. This result agreed with an investigation conducted by Hong et al. (2015) which mentioned that to optimize epoxidation yield, hydroxyl and unsaturation peak must not appear in the FTIR spectrum.

\section{NMR spectral analysis}

\section{${ }^{1} H N M R$}

Nuclear magnetic resonance spectroscopy technique is a technique used to determine a compound's unique structures by identifying a carbonhydrogen framework of an organic compound. ${ }^{1} \mathrm{H}$ NMR spectroscopy of crude oil indicated the appearance of glycerol and unsaturation in certain peaks. Glycerol is removed during the transesterification process producing methyl esters.

The spectrum of CJO, which consists mainly of triglycerides, was generated as a baseline prior to reaction. The spectrum associated with a typical glyceride profile was compared with previous works (Kouame et al., 2012; Mushtaq et al., 2013). The spectrum of CJO showed the existence of unsaturation in the range of 5.27-5.32 ppm and $2.00 \mathrm{ppm}$ and glycerol in the range of 4.0-4.27 ppm. Analysis of methyl esters shows the existence of ester peak and unsaturation, but not a glycerol peak. Formation of methyl esters was confirmed by the removal of glycerol, indicated by the disappearance of glycerol peaks at 4.07-4.28 ppm and the presence of ester peak at $3.61 \mathrm{ppm}$. After the synthesis of epoxides, the formation of products was confirmed by the disappearance of unsaturation peaks and the appearance of epoxy peaks (Fig. 6).

The ${ }^{1} \mathrm{HNMR}$ analysis confirmed the presence of dioxirane rings at $2.85 \mathrm{ppm}$ and $2.98 \mathrm{ppm}$. Moreover, unsaturation peaks were also observed to be absent in the EPJME spectrum, at $2.003 \mathrm{ppm}$ and 5.27-5.32 ppm. Similar result was reported by Borugadda and Goud (2014) during their study on the epoxidation of castor oil FAME.

${ }^{13}$ C NMR

In ${ }^{13} \mathrm{C}$ NMR analysis, unsaturation peaks existed in the range of 127.95-130.17 ppm in both CJO and JME. The characteristic peaks of ester carbonyl (-COO-) and $\mathrm{C}-\mathrm{O}$ at $174.23 \mathrm{ppm}$ and $51.36 \mathrm{ppm}$, respectively, were observed in the spectrum of the JME. The peaks in the range of 29.20-34.09 ppm are from the methylene carbons of the long carbon chain in FAME. A study on transesterification of jatropha oil by Ahmed et al. (2015) presented identical results and concluded that jatropha biodiesel is formed. As shown, unsaturation peaks were observed to be absent in the EPJME spectrum and new peaks present around 56.88-57.06 ppm were identified as the oxirane rings (Fig. 7). However, traces of unsaturation were still present with a peak at $123.96 \mathrm{ppm}$, in accordance with the percentage conversion which was around $90.8 \%$.

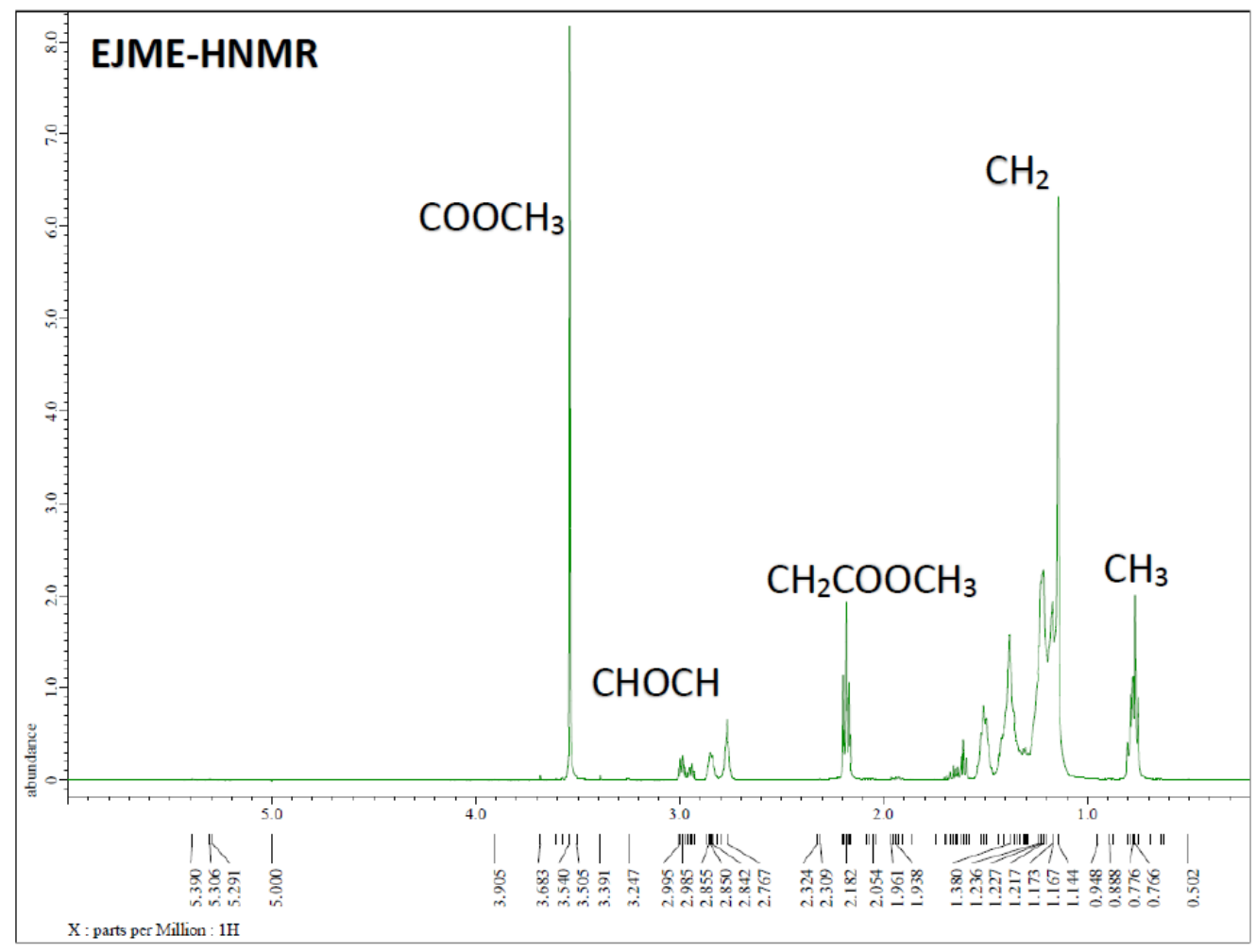

Figure 6. ${ }^{1} \mathrm{H}$ NMR spectra of EJME. 


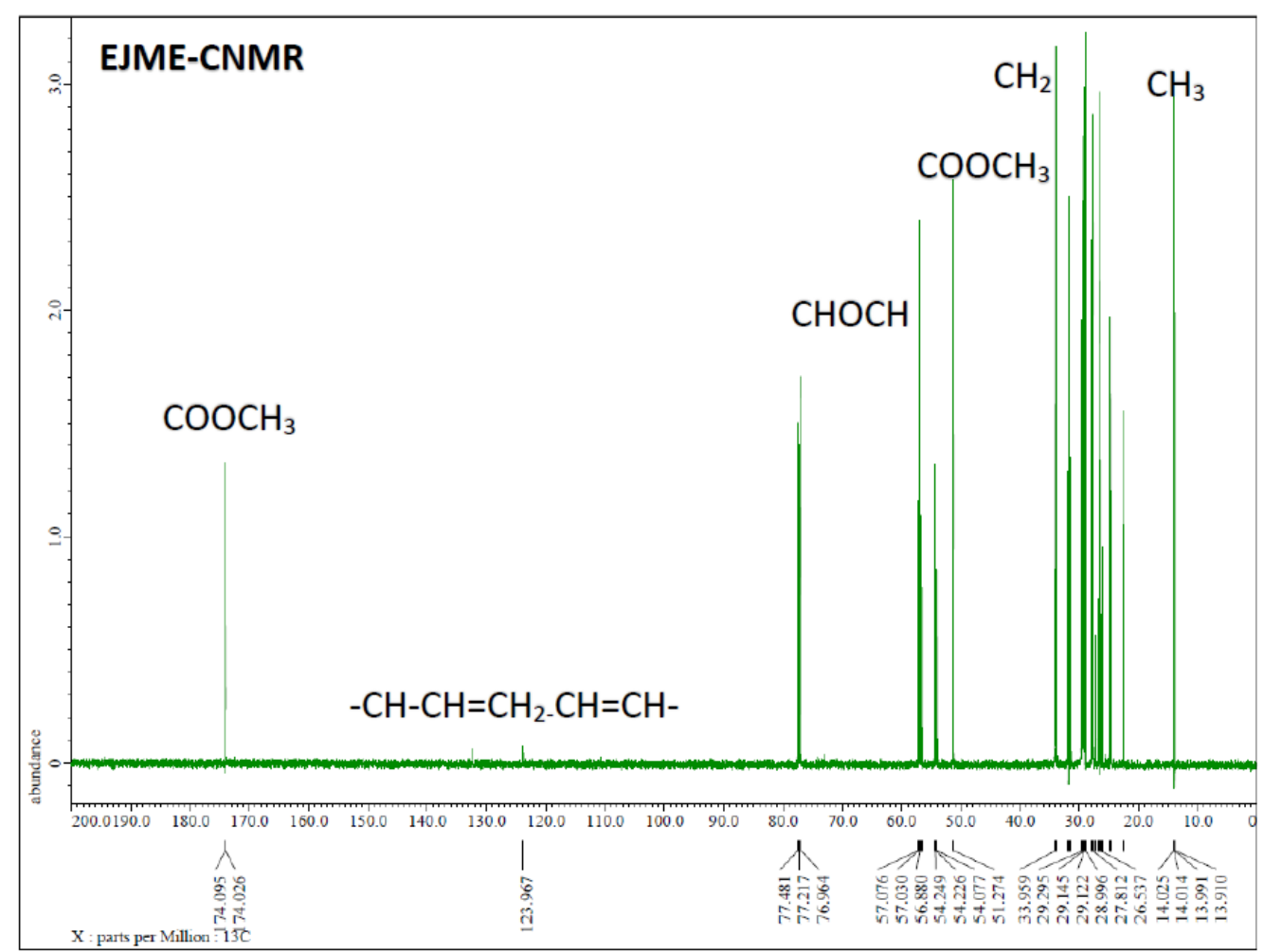

Figure 7. ${ }^{13} \mathrm{C}$ NMRspectra of EJME.

\section{CONCLUSIONS}

The epoxidation of jatropha methyl esters was carried out successfully using peroxyacetic acid generated in situ catalyzed by acidic ion exchange resin. Jatropha methyl esters are a promising alternative in the production bio-epoxides because of their physicochemical properties, availability, and versatility. It was found that the epoxidation reaction occurred optimally at a reaction temperature of $70{ }^{\circ} \mathrm{C}$ for $6 \mathrm{~h}$ with an acetic acid to unsaturation ratio of $0.5: 1$, a hydrogen peroxide to unsaturation ratio of $1.5: 1$, and a catalyst loading of $16 \%$ from the total organic phase. Under these optimum conditions, $89.9 \%$ conversion of unsaturation to oxirane was achieved. Not only did AIER provide a greener alternative for the epoxidation process, but it was also easily separated from the final product. The formation of epoxide was confirmed by FTIR and NMR spectral analysis. Based on the relative conversion to oxirane, it can be concluded that new value-added products such as bio-epoxy resins can be produced from jatropha methyl esters.

\section{ACKNOWLEDGEMENT}

The authors would like to thank the UPM Grant for Bioresins Project (Project Number: 9300427), financial contribution from Aerospace Malaysian Innovation Centre (AMIC), and also the Ministry of Higher Education for providing student assistantship.

\section{ABBREVIATIONS}

AIER

CJO

${ }^{13} \mathrm{CNMR}$

Acidic Ion Exchange Resin

EJME

FTIR

Crude jatropha oil

Carbon Nuclear Magnetic Resonance

Epoxidized jatropha methyl esters

Fourier Transform Infrared

Spectroscopy

${ }^{1}$ HNMR Proton Nuclear Magnetic Resonance

JME Jatropha methyl esters

$\mathrm{RCO}$

\section{REFERENCES}

Ahmed, W., Nazar, M.F., Ali, S.D., Rana, U.A., Khan, S.U.D. Detailed investigation of optimized alkali catalyzed transesterification of Jatropha oil for biodiesel production. Journal of Energy Chemical, 24, 331-336 (2015). https://doi.org/10.1016/S20954956(15)60319-9

Bajwa, A.S., Sathaye, S., Kulkarni, V.M., Patwardhan, A.V. Chemoenzymatic epoxidation of Karanja oil : an alternative to chemical epoxidation . AsiaPacific Journal of Chemical Engineering, 11, 314322 (2016). https://doi.org/10.1002/apj.1979

Benaniba, M.T., Belhaneche-Bensemra, N., Gelbard, G. Kinetics of tungsten-catalyzed sunflower oil epoxidation studied by ${ }^{1} \mathrm{H}$ NMR. European Journal of Lipid Science and Technology, 109, 1186-1193 (2007). https://doi.org/10.1002/ejlt.200700114 
Bobade, S.N., Kumbhar, R.R., Khyade, V.B. Preperation of Methyl Ester (Biodiesel) from Jatropha curcas Linn Oil. Research Journal of Agriculture and Forestry Science, 1, 12-19 (2013).

Borugadda, V.B., Goud, V.V. Epoxidation of Castor Oil Fatty Acid Methyl Esters (COFAME) as a Lubricant base Stock Using Heterogeneous Ion-exchange Resin (IR-120) as a Catalyst. Energy Procedia, 54, 75-84 (2014). https://doi. org/10.1016/j.egypro.2014.07.249

Borugadda, V.B., Goud, V.V. Response surface methodology for optimization of bio-lubricant basestock synthesis from high free fatty acids castor oil. Energy Science Engineering, 3, 371-383 (2015a). https://doi.org/10.1002/ese3.77

Borugadda, V.B., Goud, V.V. Improved thermooxidative stability of structurally modified waste cooking oil methyl esters for bio-lubricant application. Journal of Cleaner Production, 112, 4515-4524 (2015b). https://doi.org/10.1016/j. jclepro.2015.06.046

Campanella, A., Fontanini, C., Baltanás, M.A. High yield epoxidation of fatty acid methyl esters with performic acid generated in situ. Chemical Engineering Journal, 144, 466-475 (2008). https:// doi.org/10.1016/j.cej.2008.07.016

Carbonell-Verdu, A., Bernardi, L., Garcia-Garcia, D., Sanchez-Nacher, L., Balart, R. Development of environmentally friendly composite matrices from epoxidized cottonseed oil. European Polymer Journal, 63, 1-10 (2015). https://doi.org/10.1016/j. eurpolymj.2014.11.043

Chen, R., Zhang, C., Kessler, M.R. Polyols and Polyurethanes Prepared from Epoxidized Soybean Oil Ring-Opened by Polyhydroxy Fatty Acids with Varying OH Numbers. Journal of Applied Polymer Science, 132, 1-10 (2015). https://doi.org/10.1002/ app. 41213

Cheng, W., Liu, G., Wang, X., Liu, X., Jing, L. Kinetics of the epoxidation of soybean oil with $\mathrm{H}_{2} \mathrm{O}_{2}$ catalyzed by phosphotungstic heteropoly acid in the presence of polyethylene glycol. European Journal of Lipid Science and Technology, 117, 1185-1191 (2015). https://doi.org/10.1002/ejlt.201400614

Chua, S.C., Xu, X., Guo, Z. Emerging sustainable technology for epoxidation directed toward plant oil-based plasticizers. Process Biochemistry, 47, 14390-1451 (2012). https://doi.org/10.1016/j. procbio.2012.05.025

Cooney, T.I., Cardona, F., Tran-Cong, T. Kinetics of in Situ Epoxidation of Hemp Oil Under Heterogenous Reaction Conditions : an Overview With Preliminary Results. Energy Environment and Sustainability, 106-111 (2011).

Das, G., Karak, N. Epoxidized Mesua ferrea L. seed oil-based reactive diluent for BPA epoxy resin and their green nanocomposites. Progress in
Organic Coatings, 66, 59-64 (2009). https://doi. org/10.1016/j.porgcoat.2009.06.001

Deng, X., Fang, Z., Liu, Y. Ultrasonic transesterification of Jatropha curcas L. oil to biodiesel by a twostep process. Energy Conversion Management, 51, 2802-2807 (2010). https://doi.org/10.1016/j. enconman.2010.06.017

Dinda, S., Patwardhan, A.V., Goud, V.V., Pradhan, N.C. Epoxidation of cottonseed oil by aqueous hydrogen peroxide catalysed by liquid inorganic acids. Bioresource Technology, 99, 3737-3744 (2008). https://doi.org/10.1016/j.biortech.2007.07.015

Ghiron, C., Nannetti, L., Taddei, M. Alkene epoxidation with urea-hydrogen peroxide complex and PS-DVB supported phthalic anhydride. Tetrahedron Letters, 46, 1643-1645 (2005). https://doi.org/10.1016/j. tetlet.2005.01.074

Goud, V.V., Dinda, S., Paatwardhan, A.V., Pradhan, N.C. Epoxidation of Jatropha (Jatropha curcas ) oil by peroxyacids. Asia-Pacific Journal of Chemical Engineering, 5, 346-354 (2010). https://doi. org/10.1002/apj.285

Goud, V.V., Patwardhan, A.V., Dinda, S., Pradhan, N.C. Kinetics of epoxidation of jatropha oil with peroxyacetic and peroxyformic acid catalysed by acidic ion exchange resin. Chemical Engineering Science, 62, 4065-4076 (2007). https://doi. org/10.1016/j.ces.2007.04.038

Goud, V.V., Pradhan, N.C., Patwardhan, A.V. Epoxidation of karanja (Pongamia glabra) oil by $\mathrm{H}_{2} \mathrm{O}_{2}$. Journal of American Oil Chemists' Society, $83, \quad 635-640$ (2006). https://doi.org/10.1007/ s11746-006-1250-7

Hong, L.K., Yusop, R.M., Salih, N., Salimon, J. Optimization of the in situ epoxidation of linoleic acid of Jatropha curcas oil with performic acid. The Malaysian Journal of Analytical Science, 19, 144154 (2015).

Jain, S., Sharma, M.P. Kinetics of acid base catalyzed transesterification of Jatropha curcas oil. Bioresource Technology, 101, 7701-6 (2010). https://doi.org/10.1016/j.biortech.2010.05.034

Latif, F. E. A., Zurina, Z.. Abidin, F., Cardona, D. R., Awang Biak, P. Md., Tahir, K., Abdan, K., Liew, E. Epoxidized Jatropha Oil Blended with amine-cured epoxy resins as a hybrid bio-matrix in the biocomposite system. Journal of Engineering Science and Technology, 14, 1071- 1087 (2019).

Kay, K.H., Yasir, S.M. Biodiesel Production from Low Quality Crude Jatropha Oil Using Heterogeneous Catalyst. APCBEE Procedia, 3, 23-27 (2012). https://doi.org/10.1016/j.apcbee.2012.06.040

Kouame, S.D.B., Perez, J., Eser, S., Benesi, A. ${ }^{1} \mathrm{H}-\mathrm{NMR}$ Monitoring of the transesterification process of Jatropha oil. Fuel Processing Technology, 97, 60-64 (2012). https://doi.org/10.1016/j. fuproc.2012.01.006 
Lu, H., Liu, Y., Zhou, H., Yang, Y., Chen, M., Liang, B. Production of biodiesel from Jatropha curcas L. oil. Computers and Chemical Engineering, 33, 1091-1096 (2009). https://doi.org/10.1016/j. compchemeng.2008.09.012

May, C.A. Epoxy Resins: Chemistry and Technology. Marcel Dekker, New York (1973).

Mungroo, R., Pradhan, N.C., Goud, V.V., Dalai, A.K. Epoxidation of canola oil with hydrogen peroxide catalyzed by acidic ion exchange resin. Journal of American Oil Chemists' Society, 85, 887-896 (2008). https://doi.org/10.1007/s11746-008-1277-z

Mushtaq, M., Tan, I.M., Nadeem, M., Devi, C., Lee, S.Y.C., Sagir, M., Rashid, U. Epoxidation of methyl esters derived from Jatropha oil: An optimization study. Grasas Y Aceites, 64, 103-114 (2013). https://doi.org/10.3989/gya.084612

Okieimen, F.E., Pavithran, C., Bakare, I.O. Epoxidation and hydroxlation of rubber seed oil: one-pot multistep reactions. European Journal of Lipid Science and Technology, 107, 330-336 (2005). https://doi. org/10.1002/ejlt.200401126

Paquot, C. Standard Methods for the Analysis of Oils, Fats and Derivatives Part 1 (6th ed.). United Kingdom: Pergamon, Oxford (1979). https://doi. org/10.1016/B978-0-08-022379-7.50009-7

Petrovic, Z.S., Zlatanic, A., Lava, C., Polymer, K., Sad, N. Epoxidation of soybean oil in toluene with peroxoacetic and peroxoformic acids-kinetics and side reactions. European Journal of Lipid Science and Technology, 104, 293-299 (2002). https://doi.org/10.1002/1438$9312(200205) 104: 5 \% 3$ C 293 : : A I D EJLT293\%3E3.0.CO;2-W

Rashid, U., Anwar, F. Production of biodiesel through optimized alkaline-catalyzed transesterification of rapeseed oil. Fuel, 87, 265-273 (2008). https://doi. org/10.1016/j.fuel.2007.05.003

Rashid, U., Ibrahim, M., Ali, S., Adil, M., Hina, S., Bukhari, I.H., Yunus, R. Comparative study of the methanolysis and ethanolysis of maize oils using alkaline catalysts. Grasas Y Aceites, 63, 35-43 (2012). https://doi.org/10.3989/gya.06891

Rios, L.A., Echeverri, D.A., Franco, A. Epoxidation of Jatropha oil using heterogeneous catalysts suitable for the Prileschajew reaction: Acidic resins and immobilized lipase. Applied Catalysis A: General, 394, 132-137 (2011). https://doi.org/10.1016/j. apcata.2010.12.033

Saithai, P., Lecomte, J., Dubreucq, E., Tanrattanakul, V. Effects of different epoxidation methods of soybean oil on the characteristics of acrylated epoxidized soybean oil-co-poly ( methyl methacrylate) copolymer. Express Polymer Letters, 7, 910-924 (2013). https:// doi.org/10.3144/expresspolymlett.2013.89

Sammaiah, A., Padmaja, K. V., Badari, R., Prasad, N. Synthesis of Epoxy Jatropha Oil and its Evaluation for Lubricant Properties. Journal of Oleo Science, 63, 637-643 (2014). https://doi.org/10.5650/jos. ess 13172

Saremi, K., Tabarsa, T., Shakeri, A., Babanalbandi, A. Epoxidation of Soybean Oil. Annals of Biological Research, 3, 4254-4258 (2012).

Satyanarayana, M., Muraleedharan, C. Comparative Studies of Biodiesel Production from Rubber Seed Oil, Coconut Oil, and Palm Oil Including Thermogravimetric Analysis. Energy Sources, Part A: Recovery, Utilization and Environmental Effects, 33, 925-937 (2011). https://doi. org/10.1080/15567030903330637

Sinadinović-Fišer, S., Janković, M., Borota, O. Epoxidation of castor oil with peracetic acid formed in situ in the presence of an ion exchange resin. Chemical Engineering Process. Process Intensification, 62, 106-113 (2012). https://doi. org/10.1016/j.cep.2012.08.005

Wang, R., Schuman, T.P. Vegetable oil-derived epoxy monomers and polymer blends: A comparative study with review. Express Polymer Letters, 7, 272-292 (2012). https://doi.org/10.3144/ expresspolymlett.2013.25 